\title{
Student teachers' attitudes towards and willingness to teach evolution in a changing South African environment
}

\author{
A. L. Abrie \\ Department of Science, Mathematics and Technology Education, Faculty of Education, \\ University of Pretoria, South Africa.
}

\begin{abstract}
This article investigates the attitudes of South African student teachers towards the theory of evolution and their willingness to teach it. The teaching of evolution has been excluded from the South African school curriculum for most of the 20th century. In 2008, Grade 12 learners were for the first time exposed to the concept of evolution in the Life Sciences curriculum. The participants in this study completed school prior to 2008 and thus have to interpret this curriculum with no or very little training in this topic. A questionnaire consisting of Likert-style and open-ended questions was administered to student teachers who intend to become secondary school biology teachers. A large percentage of the participants were found to reject the theory of evolution. In addition, the majority indicated that they are religious. Those who were more observant were more likely than their less observant counterparts to find evolution incompatible with their belief system and to renounce the theory of evolution. Although $70 \%$ of the participants felt that they were adequately prepared to teach evolution, the data shows that these student teachers have a poor understanding of evolution theory and that they harbour many misconceptions. In fact, less than half of the students support the teaching of evolution in South African schools. The article concludes with a number of recommendations.

Key words: Evolution, education, student teachers, attitudes, science/religion controversy.
\end{abstract}

\section{Introduction}

Most biologists consider evolution to be the central ordering principle or theory of the life sciences and assume a working knowledge of the Darwinian paradigm as a matter of course (Dempster and Hugo, 2006). The theory of evolution is described as the unifying framework of the life sciences that describes not only the history of life, but also current changes that occur in organisms (National Association of Biology Teachers, 1995). Although some debate exists regarding aspects such as the mechanisms through which evolution works, the basic theory is well established and non-controversial within the scientific community (Rutledge and Warden, 2000). In contrast, the concept of evolution is still unacceptable to a large percentage of the South African population. No figures are available, but the exclusion of the topic from the South African school curriculum for most of the 20th century indicates a strong rejection not only on the part of the previously segregated departments of education, but by the public at large.

\section{The history of teaching evolution in South Africa}

When Darwin published On the origin of species in 1859, the prevailing paradigm in South Africa was creationism.
Evolution was perceived as an attack on the Biblical view of creation and the absolute sovereignty of God (Lever, 2002; Dempster and Hugo, 2006). As a consequence, all reference to evolution was kept out of the South African school curriculum, until 1947 when it appeared as part of a brief section on historical figures in science. During the mid-1950s even this disappeared from the curriculum and the Biology curriculum stated that one of its aims was

"to develop, through contact with the subject matter, a reverence for the Creator and an esteem for the wonders of the created universe" (Cape Education Department syllabi 1973 to 1996 as cited in Lever, 2002).

As a result schools did not so much teach an antiscience or anti evolution message as negate the theory of evolution completely.

During the Apartheid years (1948-1994), Afrikaner Nationalism found expression not only in the political system, but also in education. This led to the development of Christian National Education (CNE), which formed the basis for National Education between 1967 and 1994. CNE required not only racial segregation, but that all education should be based on Christian 
principles (Christie, 1991; Esterhuysen and Smith, 1998; Lever, 2002). Christian religious instruction became compulsory in schools and anti-Biblical concepts such as evolution were not tolerated in the curriculum (Esterhuysen and Smith, 1998). The hidden curriculum therefore made lectures on creation, patriotism, race relations and religion part of the everyday school experience of learners. The Minister of Native Affairs at the time, Hendrik Verwoerd, stated that Blacks did not need education as there was no place for them 'above the level of certain forms of labour' and that 'they should be educated for their opportunities in life' (Christie, 1991). This provided a rationalisation for the Bantu Education Act of 1953 that was intended to keep Black education sub-standard.

The influence of CNE and Bantu Education was especially detrimental to school science. The study of the sciences was discouraged in black schools, as science did not fit into the 'forms of labour' deemed acceptable for black people. At the same time, the content-based science curriculum for white schools was influenced strongly by the creeds of the Afrikaans Reformed churches, which required that the 'spirit and direction in every subject taught must correspond to the Christian and national life- and world-view' (Instituut vir Christelik-Nasionale Onderwys, 1948 as cited in Lever, 2002). As a result - for most of the previous century neither curricula designed for Bantu Education nor those intended for the education of whites made any reference to the theory of evolution.

\section{Teaching of evolution in post Apartheid South Africa}

In 1994, the political system changed dramatically with the establishment of the first democratic government in South Africa. One of the first priorities of the new government was to reform the education system. Segregation in government-sponsored schools officially came to an end at the beginning of the 1995 school year and curriculum reforms were initiated. Today, the Revised National Curriculum Statement: Natural Sciences for Grades R-9 (RNCS) (Department of Education, 2002) and the National Curriculum Statement for Grades 10-12 (NCS) (Department of Education, 2003) direct the school curriculum.

In the RCNS, 17\% (11 out of the 66) of the prescribed content statements for Grades 7 to 9 can be linked to concepts related to the theory of evolution, although the word 'evolution' is carefully avoided - the only references are to 'change over time' or 'development'. Concepts include the non-constancy of the environment and life on earth, the process of natural selection, extinction, adaptation, biodiversity and classification, but the curriculum fails to provide a map that describes how to put these concepts together to explain the theory of evolution adequately. The core concept of 'natural selection' is erroneously described as nature deliberately killing those less well adapted, rather than as a differential survival and reproduction. If a teacher allocates equal amounts of time to each of the content areas, 17 hours per grade per year will be spent on the teaching of these topics (Dempster and Hugo, 2006). The NCS (Grades 10-12) introduces the word 'evolution' into the curriculum. About a quarter of the content for Grade 12 covers ideas and concepts relevant to evolution; this implies about 40 hours of teaching time (Dempster and Hugo, 2006). This part of the curriculum was implemented in 2008.

\section{Research Questions}

Little is known about the current attitudes and knowledge of South African teachers and student teachers (pre-service teachers) regarding evolution. It is against this background that this exploratory study sought to investigate the following main questions:

- What are the attitudes of student teachers at a historically Afrikaans South African university towards the theory of evolution?

- How willing are student teachers to teach evolution in South African schools?

\section{Methodology}

A questionnaire was developed, based on similar questionnaires found in the literature (Downie and Barron, 2000; Rutledge and Warden, 2000; Moore and Kraemer, 2005). Some open-ended questions about the student teachers' academic and religious backgrounds were added. The instrument was scored using a Likert scale, with choices that ranged from strongly agree, agree, undecided, disagree to strongly disagree and a number of open-ended questions. A 22-item subscale, referred to as the Acceptance of Evolution subscale, addressed the extent to which students felt that they could accept the theory of evolution; whether evolution was in conflict with their belief system; the importance of the theory of evolution to the life sciences, and whether evolution was a scientifically valid theory or not. A few items determined the extent to which these students supported some of the common misconceptions regarding the theory of evolution. The rest of the questionnaire explored whether students thought that the theory of evolution should be taught in South African schools and who should decide whether it should be taught.

The instrument was examined by several academics in order to establish face validity and construct validity. These individuals included life science specialists, a geologist with a special interest in evolution and a chemist with a strong religious background. The reliability of the instrument was established by determining Cronbach's Alpha and using SPSS for the analysis.

Written ethical clearance was sought and obtained from the Ethics Committee of the Faculty of Education prior to the administration of the questionnaire. During the second half of 2007, first-, second- and third-year students who were training to become biology teachers and who studied in the Faculty of Education at a large, historically Afrikaans, South African university were invited to complete the questionnaire. (These students 
have all completed their school education prior to the implementation of the NCS.) Participation in the study was voluntary. Students were expected to sign an ethical consent form prior to their participation and to return these with their questionnaires. They were asked to fill in the questionnaires in their own time and to return them anonymously to the departmental assignment box.

\section{Results}

A total of 46 completed questionnaires were returned. Seventy-six percent of the samples were females, with an average age of 21.

The Acceptance of Evolution subscale had a Cronbach Alpha of 0.895, which indicates that the items of the instrument are highly related and that they all measure the same psychological construct. Responses in the categories strongly agree and agree were combined to reflect agreement with items, while strongly disagree and disagree were combined to reflect disagreement. The frequency of responses was calculated and correlation coefficients were calculated between some of the items.

Only $40 \%$ of the students in this survey indicated that they accepted the theory of evolution, 12\% were uncertain and 48\% did not accept evolution. The majority of the students also reported that they were religious. Only three students did not belong to a faith, one student was Hindu and 89\% of students were Christian. Altogether 52\% $(n=24)$ of the students attended religious activities once a week or more. In the rest of this article, this group is referred to as the more observant group. The low number of non-religious students prevented an analysis to determine whether religious and non-religious students differed in their attitudes towards evolution. However, data obtained from the more observant group was compared to data from students who attended religious activities less often. Acceptance of evolution in the latter group was $55 \%$, but only $37 \%$ in the more observant group. In this sample, $87 \%$ of the students indicated that they believe that 'God, the Almighty created all living things as we know it' and half of the group considered the theory to be incompatible with their belief systems. A strong negative correlation of $r=-0.6$ was found between 'I accept the theory of evolution' and 'The theory of evolution cannot be correct since it disagrees with the Biblical/my religion's account of creation'. Students did not only experience conflict between different accounts of the origin of life, but nearly half (48\%) experienced conflict between religion and science in general.

Despite the low acceptance of evolution, 76\% agreed that it was important for biology/life science teachers to understand the theory of evolution well and 59\% thought it was important to understand this theory in order to make sense of the life sciences in general. Nevertheless, the well-known statement that Dobzhansky used as the title of his 1973 article,

"Nothing in Biology makes sense except in the light of evolution", was supported by a mere $22 \%$ of the students.

Although $70 \%$ of the participants considered

themselves adequately prepared to teach evolution, the data does not support this. Their responses made it clear that they neither had a satisfactory knowledge of the theory of evolution, nor did they understand the nature of science. The respondents could be divided into two groups: those who accepted the scientific validity of evolution (41\%), and those who rejected it on the basis that it is 'just an idea with little merit', that 'the evidence is full of conflicts and contradictions' and that 'it is based on speculation and not valid scientific observation and testing'. A correlation of $r=0.58$ was found between acceptance of the scientific validity of the theory of evolution and acceptance of the theory itself. Acceptance of the scientific validity also showed high positive correlations (both $r=0.7$ ) with items stating 'Evolutionary theory generates testable predictions with regard to the characteristics of life' (supported by $52 \%$ of participants) and 'There is a significant body of data which supports evolutionary theory' (supported by 59\%).

The item 'The theory of evolution is just an idea with little merit' was rejected by $44 \%$ of participants, but supported by $28 \%$. In the more observant group, $42 \%$ chose the option 'undecided'. This statement correlated well with 'The theory of evolution is based on speculation and not valid scientific observation and testing' ( $r=0.66)$, but correlated negatively with 'I accept the theory of evolution' $(r=-0.65)$, 'There is a significant body of data which supports evolutionary theory' $(r=-0.6)$ and 'I accept evolution as a scientifically valid theory' $(r=-0.5)$.

Common misconceptions regarding the theory of evolution received support from many of the participants; $46 \%$ felt that only the strongest survives, $35 \%$ saw evolution as a purposeful development of higher forms and 57\% thought that man developed from lower primates such as the gorilla and the chimpanzee. Only 54\% agreed that the earth is more than 6,000 years old and $41 \%$ indicated that the earth was in fact more than 4 billion years old. In the more observant group $42 \%$ were undecided about this last item.

Although $52 \%$ of the students accepted the more general statement that organisms have evolved over millions of years, 35\% indicated that modern humans are the product of evolutionary processes that have occurred over millions of years. In the more observant group, only $25 \%$ agreed that humans have evolved, while 29\% were undecided. This suggests that these students either do not know how to evaluate the evidence for human evolution or that they do not consider humans to be part of the story of evolution.

The students who participated in this survey did not support the idea that evolution should be taught in South African schools. Less than $50 \%$ of this sample felt that the Department of Education should make the decision whether or not evolution should be taught in schools. This is surprising, given the fact that these students are all being trained to become teachers and should be familiar with the role that the Department usually plays in determining the content of the curriculum. They were especially concerned about the 
position of teachers and learners who did not support evolution and felt that they should be able to choose not to be involved with the teaching and learning of the topic. When asked who should be able to determine whether the theory of evolution should be taught in South African schools, 30\% indicated that the decision should be left to school governing bodies, $48 \%$ preferred to heed the wishes of the parents and 65\% thought that the decision should reside with the teachers themselves. The students did not agree that a teacher who disagrees with the theory should be forced to teach it (65\%).

A negative correlation $(r=-0.64)$ was found between acceptance of the theory and a proposition that teachers should have a choice whether to teach the topic. Although $74 \%$ of the students indicated that learners have the right to learn about evolution in the science powerful influence on their (non-)acceptance of the theory. Their views and (lack of) knowledge of the subject content are likely to have an impact on their pedagogy and consequently on the learners in their classrooms (Trani, 2004). Ausubel's (1968) dictum, that 'The most important single factor influencing learning is what the learner already knows. Ascertain this and teach him accordingly', is relevant to the teaching of evolution in a situation where the teachers themselves have not benefited from being taught these concepts during their own education. Many of these future teachers have deeply held religious views that are in conflict with the theory of evolution; beliefs that they will most likely retain in spite of instruction and beliefs that are likely to interfere with successful teaching once they are qualified.
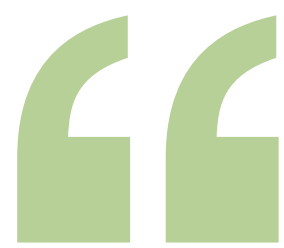

many learners come to the classroom with ...religious beliefs...

\section{in conflict with science}

class, only $42 \%$ thought it should be a compulsory part of the curriculum and $44 \%$ felt that learners should have a choice whether or not to attend classes where evolution is taught. In contrast, the support for religious studies was strong and unambiguous and the compulsory teaching of religion was supported by $63 \%$ of the students. It is not clear how much the students know about the creationism and intelligent design debates that are prevalent in the United States, but 52\% thought that these ideas should be taught in South African schools, or that evolution should at least be taught alongside these ideas (50\%).

\section{Discussion}

Although this was a small study conducted at a single university, the data reveals that acceptance of the theory of evolution in this cohort of students is low. It is possible that the data was biased, as participation was voluntary and questionnaires were filled in anonymously. Perhaps those who are more supportive of the theory of evolution were more (or less) likely to participate. However, based on the findings that emerged even from this small sample, it is clear that acceptance of evolution by student teachers and teachers should be investigated further. All the students in the sample are studying to become biology teachers. The fact that the topic of evolution was totally excluded from their school curriculum has had a
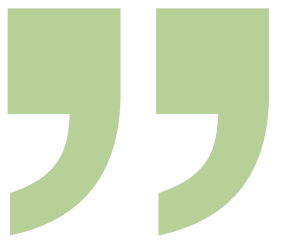

creationist in Italy. Miller et al, (2006) conducted a survey among adults and found that rejection of evolution is significantly lower in 32 European countries than in the USA. More than 80\% of adults in Denmark, Iceland, Sweden and France thought evolution was either definitely or at least probably true, compared to $40 \%$ of Americans. Only Turkish adults were less likely to accept evolution than adults in America. This trend is also seen in students enrolled for introductory biology courses. In a study conducted over a period of twelve years, the percentage of Scottish students rejecting evolution declined from $11 \%$ to $4 \%$ (Downie and Barron, 2000), but in the USA $24 \%$ of students in a similar course rejected the theory (Grose and Simpson, 1982). Many teachers in America reject evolution and embrace creationism, but this figure varies from study to study and from state to state (Rutledge and Warden, 2000; Trani, 2004; Moore and Kraemer, 2005). The current study shows that the percentage of South African student teachers who reject evolution is higher than in any of these groups.

Teachers determine the quality of instruction in their classroom. It is therefore vital that they make professionally responsible instructional and curricular decisions (Rutledge and Mitchell, 2002). Many of the students in this study supported common misconceptions and showed a lack of understanding of the nature of science. They were not able to evaluate 
claims about the scientific validity of evolution. Rutledge and Mitchell (2002) argue that such teachers will not be able to evaluate the strongly argued, often emotional arguments from those with strongly held religious views.

It is not known to what extent acceptance and knowledge of evolution will influence the quality of teaching and the time spent on evolution in the classroom. While the NCS prescribes what should be taught in the biology classroom and how much time should be spent on each topic, this is no guarantee that the guidelines will be followed. Increased teacher acceptance has been linked to increased time spent on

Darwin dominates the biological sciences, but for many pupils, and teachers, the theory of evolution may be culturally unacceptable.

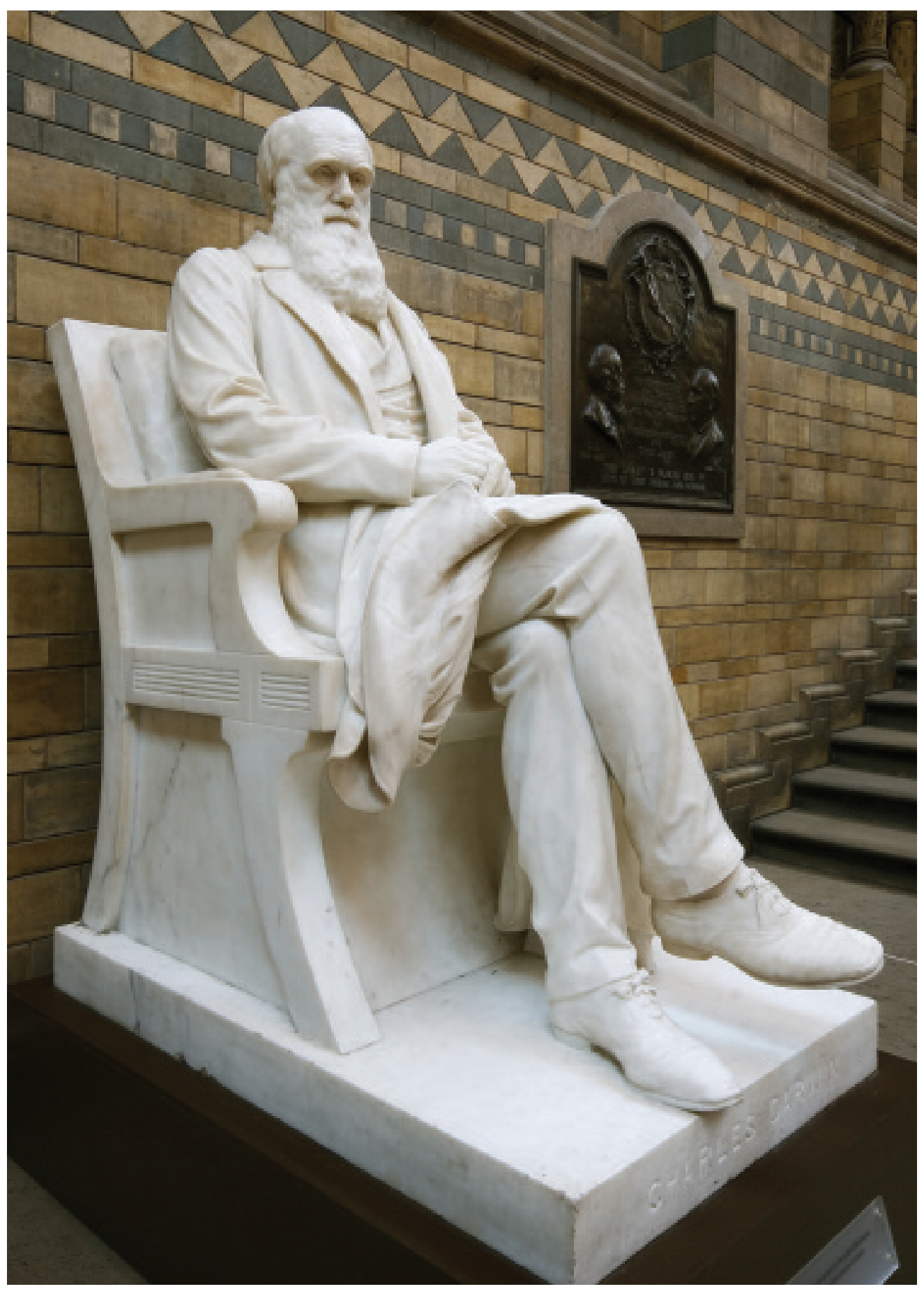

teaching the topic (Rutledge and Mitchell, 2002; Trani, 2004), but acceptance in this sample of students was low.

Numerous studies have indicated that religion is a stumbling block to the acceptance of evolution (Grose and Simpson, 1982; Downie and Barron, 2000; Rutledge and Mitchell, 2002; Trani, 2004). The data presented here indicates that this is also true for the student teachers in this study. With only $15 \%$ of the South African population indicating that they are not religious and nearly 80\% claiming to be Christian (South Africa.Info, 2007), the religion/science controversy is likely to play out in classrooms. Trani (2004) suggests that the stronger a teacher's religious convictions, the less likely he/she is to teach evolution, even when it is required by law. The data in this study shows that the majority of these students are unwilling to teach evolution as a compulsory part of the curriculum.

In the South African Life Science curriculum, specific mention is made of 'beliefs about creation and evolution' (Department of Education, 2003).

Furthermore, the curriculum refers to indigenous knowledge systems and places all knowledge domains on an equal footing. While many would argue that creationism should not form part of the valid science curriculum (National Association of Biology Teachers, 1995), Cooper (1996) argues that it is impossible to avoid the discussion of creation beliefs in the context of a discussion on evolutionary biology. Even if it was not raised by teachers themselves, it will be brought up by the learners. It would therefore be irresponsible not to address these issues. The danger is that this will allow teachers with a religious bias to introduce creationism as a respectable, scientific alternative to evolution, although it does not meet the criteria necessary for it to be considered a scientific theory.

Should many of the student teachers who 
participated in this study come to teach evolution, their presentation would inevitably include many

inaccuracies. It is quite possible that these teachers, like many of their American counterparts, will either avoid or only briefly mention evolution in their biology classes (Rutledge and Mitchell, 2002, Trani, 2004; Moore and Kraemer, 2005). It is also possible that they will actively teach a creationist viewpoint and deal with evolution only reluctantly as a compulsory part of the curriculum, instead of it being the cornerstone of modern biology.

\section{Educational implications}

Improving the understanding of evolution of future biology teachers should be a priority of teacher training programmes. Specific attention should be given to those students and teachers who themselves have not been exposed to the topic of evolution during their school years. A critical evaluation of training programmes for biology teachers is urgently needed. Evolution instruction in biology courses should be commensurate with the theory's significance as a central organising principle of the biological sciences (American Association for the Advancement of Science, 1989). Specific courses in both evolution and the nature of science should be a requirement for the subject matter preparation for biology teachers. It is essential that teacher training programmes should focus on both the substantive structure (concepts and propositions of the discipline) and the syntactic structure (means by which knowledge is generated, in this case the nature of science) (Rutledge and Mitchell, 2002). Current teachers who have not been exposed to the theory of evolution during their previous training should also be offered opportunities for re-training.

The curriculum statement provides core knowledge and concepts for $80 \%$ of the content that should be taught, but allows the other $20 \%$ to be 'used by provinces and schools to adapt specified knowledge to local conditions or to incorporate local knowledge into the curriculum' (Department of Education, 2003). The lack of understanding of the theory of evolution suggests that these future teachers will probably struggle to find and evaluate such content. Detailed instructional material should be made available to all teachers. It should be prepared by professionals who do not only have knowledge of evolution, but also of the general misconceptions that exist about the topic and of good instructional practices that will enhance the teaching and learning of evolution. The availability of instructional material does not in itself guarantee that teaching will improve and should thus be augmented with specific development programmes.

In the South African situation where many learners come to the biology classroom with deeply held religious beliefs that are to them in conflict with science, learning will be hindered unless these issues are brought into the open. Again, teachers should be provided with both instructional materials and with development opportunities that will provide them with the information they need to deal with these conflicts in their classrooms.
It might not be possible to change many minds, but learners would at least be encouraged to explore the issues with more information at their disposal.

\section{Acknowledgements}

The author wishes to thank Prof. Kobus Maree and Dr Cecilia du Toit for their help in preparing this article and Dr Vanessa Scherman for her statistical assistance. This work was made possible through funding provided by the Research Development Programme of the University of Pretoria, which is gratefully acknowledged.

\section{References}

American Association for the Advancement of Science (1989) Project 2061: Science for all Americans. Washington, DC: AAAS.

Ausubel D P (1968) Educational Psychology: A Cognitive View. New York: Holt, Rinehart and Winston.

Christie P (1991) The right to learn. Cape Town: Ravan Press/ SACHED Trust.

Cooper R A (1996) Should Creationism be part of Evolution Statement? The American Biology Teacher. 58(3) 133-134.

Dempster E R and Hugo W (2006) Introducing the concept of evolution into South African Schools. South African Journal of Science. (102) 106-112.

Department of Education (2002) Revised National Curriculum Statement for Grades R-9 (Schools): Natural Sciences. Department of Education, Pretoria.

Department of Education (2003) National Curriculum Statement Grades 10-12 (General): Life Sciences. Department of Education, Pretoria.

Dobzhansky T (1973) Nothing in biology makes sense except in the light of evolution. The American Biology Teacher. (35) 127-129.

Downie J R and Barron N J (2000) Evolution and religion: attitudes of Scottish first year biology and medical students to the teaching of evolutionary biology. Journal of Biological Education, 34(3) 139-146.

Esterhuysen A and Smith J (1998) Evolution: The forbidden word? The South African Archaeological Bulletin. (53) 135-137.

Grose E C and Simpson R D (1982) Attitudes of introductory college biology students toward evolution. Journal of Research in Science teaching. 19(1) 15-24.

Lever J (2002) Science, evolution and schooling in South Africa. In The architect and the scaffold: Evolution and Education in South Africa, eds. W James and L Wilson. Cape Town, HSRC.

Miller J D, Scott E C and Okamoto S (2006) Public Acceptance of Evolution. Science. (313) 765-766.

Moore R and Kraemer K (2005) The teaching of evolution and creationism in Minnesota. The American Biology Teacher. 67(8) 457-465.

National Association of Biology Teachers (1995) NABT's Statement on Teaching Evolution. http://www.nabt.org/websites/institution/ index.php? $=92$. Accessed on 2009-07-31.

Pigliucci M (1997) The new anti-evolution. Trends in Ecology and Evolution. 12(6) 228.

Rutledge M L and Warden M A (2000) Evolutionary theory, the nature of science and high school biology teachers: Critical relationships. The American Biology Teacher. 62(1) 23-31.

Rutledge M L and Mitchell M A (2002) High school biology teachers' knowledge structure, acceptance and teaching of evolution. The American Biology Teacher. 64(1) 21-28.

South Africa.Info (2007) South Africa: Fast facts. http://www.south africa.info/about/facts.htm. Accessed on 2009-07-31.

Trani R (2004) I won't teach evolution; It's against my religion. And now for the rest of the story ... The American Biology Teacher. 66(6) 419-427.

A. L.Abrie is a Lecturer at the Department of Science, Mathematics and Technology Education, Faculty of Education, University of Pretoria, South Africa. Tel +27(0)12420 5569. E-mail:Mia.Abrie@up.ac.za 
Copyright of Journal of Biological Education is the property of Institute of Biology and its content may not be copied or emailed to multiple sites or posted to a listserv without the copyright holder's express written permission. However, users may print, download, or email articles for individual use. 